\title{
CROP YIELD AND FERTILIZERS PREDICTION USING DECISION TREE ALGORITHM
}

\author{
T. Nikhil Yadav \\ Department of CSE \\ Institute of Aeronautical Engineering, \\ Hyderabad, Telangana, INDIA. \\ Ram Chandra Prasad \\ Department of CSE, \\ Institute of Aeronautical Engineering, \\ Hyderabad, Telangana, INDIA.
}

\begin{abstract}
In India most of the people ultimately depends on agriculture, some percentage of people directly occupied by farming while other does trading with final products. India is producing huge amount of food grains which have great effect on Indian economy. Data Mining is sky rocketing in the field of crop production. Every farmer is interested in knowing about the yield he is about to get. This study will attempt to quantify past weather and technological factors, analyze their effects on yields and predict future crop yield based on season, area, temperature, humidity, moisture, amount of nutrients value of potassium, nitrogen and phosphorous. Then all these factors are divided into training and test datasets and tested with different machine learning models. By this model we can accurately predict the crop yield and fertilizer to be used in the area of land, as a result it will help the agronomist to increase their income and improve country's economy.
\end{abstract}

Keywords - Random forest Regression, Decision tree Regression, definite prediction.

\section{INTRODUCTION}

Indian agriculture sector gives huge employment in different fields of cultivation industry. India cultivates many different kinds of crops, but produces more amounts of rice and wheat. Indian agronomist also farm urad, jowar, small millets, sugarcane and non food crops like hemp, jute, cotton. But nowadays the weather conditions of the atmosphere are not stable like previous days, because of global warming and other man made calamities. The weather conditions are highly unstable and are very difficult for the farmers to rely upon the traditional agricultural techniques.

\author{
Dr. R Obulakonda Reddy \\ Department of CSE, \\ Institute of Aeronautical Engineerning, \\ Hyderabad, Telangana, INDIA. \\ Pradeep Gopal \\ Department of CSE, \\ Institute of Aeronautical Engineering, \\ Hyderabad, Telangana, INDIA.
}

The farmers need more effective measures for predicting the weather conditions which in order gives the farmers a better crop yield. Indian agriculture mainly depends on rainfall and ground water availability. According to Rahul tangia (2019) crop production of India is decreasing per capital compared to other countries as show in fig 1 .

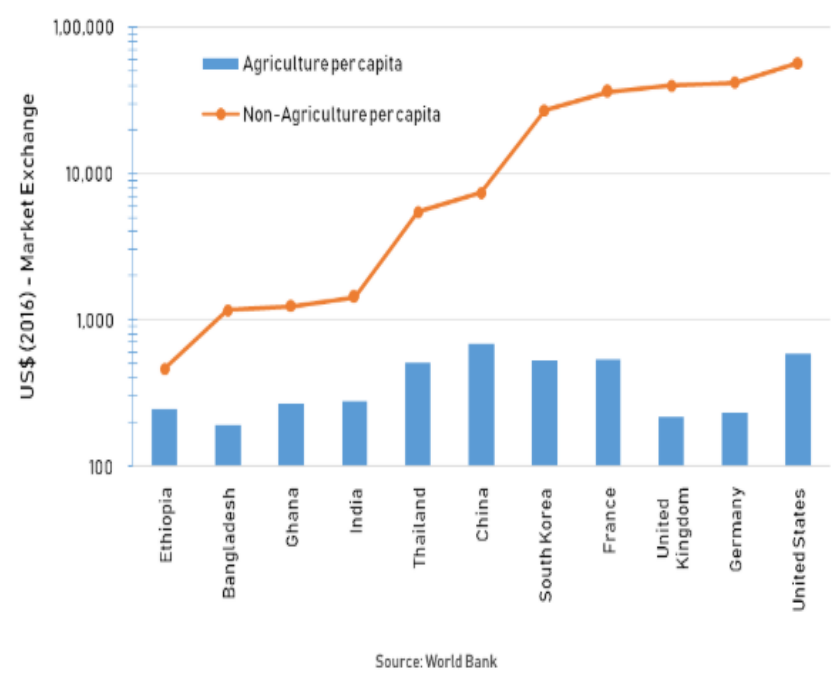

Fig. 1 GDP per capita

If we are able to predict the specific crop production at a particular land it will be very useful to the farmer to choose a specific crop to cultivate, as a result crop production capital will increase. In India there are fifteen agro climatic regions and these agro climatic regions are separated into groups based on season, type of land, temperature, soil type and its fertility. By considering these factors we can help the agronomist to predict the yield of a crop and suggest fertilizers to framer which he can use in the field. Generally, framer predicts the production by using traditional methods and experience, but due to climatic changes agronomist are unable 


\section{International Journal of Engineering Applied Sciences and Technology, 2020 \\ Vol. 5, Issue 1, ISSN No. 2455-2143, Pages 187-193 \\ Published Online May 2020 in IJEAST (http://www.ijeast.com)}

to predict the yield. By using different machine learning models we can predict the most accurate output of the yield.

\section{LITERATURE SURVEY}

Niketa Gandhi et al. (2016) have used different classifiers and showed that LADTree and J48 classifiers have showed sky-high accuracy, however SMO classifiers are less definite than other family of classification like naïve bayes. Here mainly four factors that were taken are precipitation, average temperature, maximum temperature and minimum temperature to predict crop yield. This system has only analyzed rice crop data which made the model limited to use, as shown in fig 2.

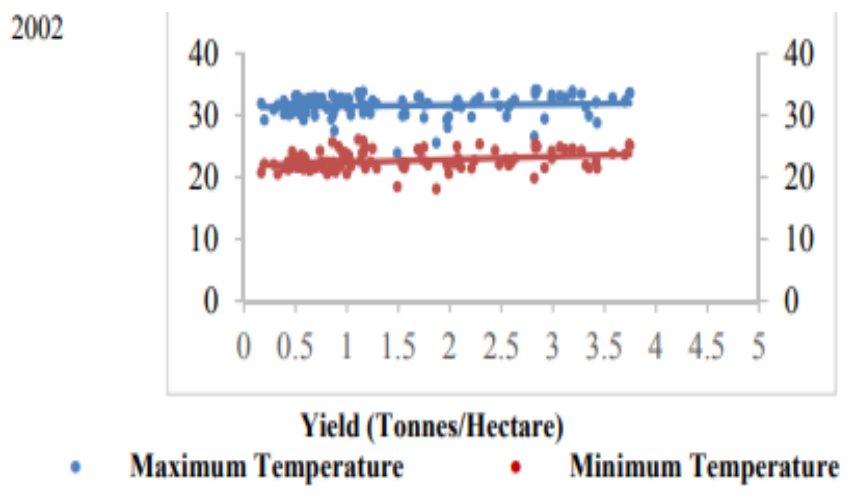

Fig. 2 Prediction of rice crop yield

K.E. Eswari et al. (2018) has used Baysian Network to predict the yield and proved that Naive Bayes classifier has more accurate rate compare to sequential minimal optimization classifier. In model author has taken seven factors as show in fig 3 .

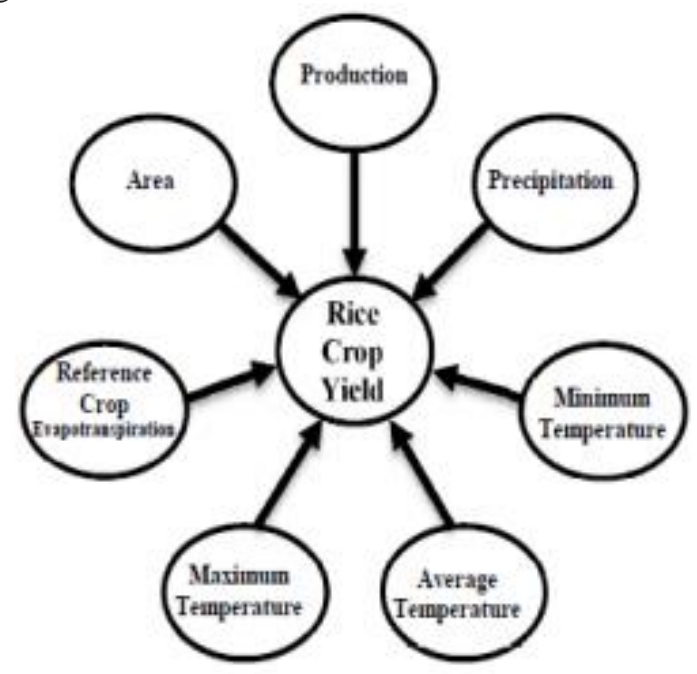

Fig. 3 Dataset attributes
Additional factor consider in this model is evapotranspiration, which is combination of evaporation as well as transpiration and responsible for absorption water vapors from plants. In this classification model prediction is done by using two classes which are true class and false class and further divided into true negative, true positive, false negative and false positive as shown in fig 4 .

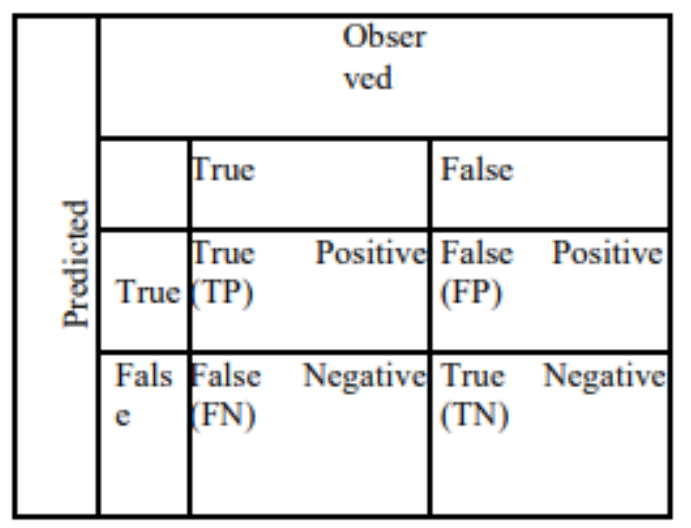

Fig. 4 Classification classes used in Baysian Network

Shruti Mishra et al. (2018) used various data mining classifiers such as Instance Based Learner (IBK), Locally Weighted Learning (LWL), LADTree and J48 to predict the production of crop. They have considered several factors like name of district, year of crop, name of the season, name of crop, area and these factors are pre-processed and classified in WEKA explorer. They have predicted error rate by using Root Mean Squared Error, Mean Absolute Error and Relative Absolute Error as shown in fig 5.

\begin{tabular}{|l|c|c|c|}
\hline Algorithm & RMSE & MAE & RAE (\%) \\
\hline J48 & 0.2773 & 0.1101 & 37.9755 \\
\hline LWL & 0.3209 & 0.2213 & 76.3471 \\
\hline LAD Tree & 0.4127 & 0.1997 & 68.8888 \\
\hline IBK & 0.3057 & 0.104 & 35.8648 \\
\hline
\end{tabular}

Fig. 5 Error Rate

As per author [1] J48 classifier have got higher accuracy but in this proposed model Instance Based Learner classifier (IBK) got higher accuracy as shown in fig 6. 
Published Online May 2020 in IJEAST (http://www.ijeast.com)

\begin{tabular}{|l|l|}
\hline Algorithm & Accuracy (\%) \\
\hline J48 & 78.145 \\
\hline LWL & 66.225 \\
\hline LAD Tree & 62.251 \\
\hline IBK & 80.794 \\
\hline
\end{tabular}

Fig. 6 Accuracy percentage

\section{IMPLEMENTATION METHODOLOGY}

Estimating the production of crop using the potent algorithm and prediction of which type of fertilizer to be used on crop

\section{A. Data Set Explanation}

In this model we are utilizing two datasets. Fig 7 is for prediction of crop yield, this data frame consists of six factors which are trained by various machine learning techniques to predict the production of crop and from fig 8 we can predict the fertilizer name which should be used for better yield of a crop. Fertilizer prediction is based on six factors; these factors are temperature, humidity, moisture, nitrogen, potassium and phosphorous.

\begin{tabular}{|c|c|c|c|c|c|}
\hline $\begin{array}{l}\text { State_Name } \\
\text { Andaman and } \\
\text { Nicobar Isla... }\end{array}$ & $\begin{array}{l}\text { District__Name } \\
\text { NICOBARS }\end{array}$ & $\begin{array}{l}\text { Crop_Year } \\
2000\end{array}$ & $\begin{array}{l}\text { Season } \\
\text { Kharif }\end{array}$ & $\begin{array}{r}\text { Crop } \\
\text { Arecanut }\end{array}$ & $\begin{array}{c}\text { Area } \\
1254.0000000\end{array}$ \\
\hline $\begin{array}{l}\text { Andaman and } \\
\text { Nicobar Isla... }\end{array}$ & NICOBARS & 2000 & Kharif & $\begin{array}{l}\text { Other Kharif } \\
\text { pulses }\end{array}$ & 2.000000 \\
\hline $\begin{array}{l}\text { Andaman and } \\
\text { Nicobar Isla... }\end{array}$ & NICOBARS & 2000 & Kharif & Rice & 102.000000 \\
\hline $\begin{array}{l}\text { Andaman and } \\
\text { Nicobar Isla... }\end{array}$ & NICOBARS & 2000 & Whole Year & Banana & 176.000000 \\
\hline $\begin{array}{l}\text { Andaman and } \\
\text { Nicobar Isla... }\end{array}$ & NICOBARS & 2000 & Whole Year & Cashewnut & 720.000000 \\
\hline $\begin{array}{l}\text { Andaman and } \\
\text { Nicobar Isla... }\end{array}$ & NICOBARS & 2000 & Whole Year & Coconut & 18168.000000 \\
\hline
\end{tabular}

Fig. 7 Sample crop data

\begin{tabular}{|l|l|l|l|l|l|}
\hline Temparature & Humidity & Moisture & Nitrogen & Potassium & Phosphorous \\
\hline 26 & 52 & 38 & 37 & 0 & 0 \\
\hline 29 & 52 & 45 & 12 & 0 & 36 \\
\hline 34 & 65 & 62 & 7 & 9 & 30 \\
\hline 32 & 62 & 34 & 22 & 0 & 20 \\
\hline 28 & 54 & 46 & 35 & 0 & 0 \\
\hline
\end{tabular}

Fig. 8 Sample fertilizer data

\section{B. Necessary Packages}

- Numpy

- Pandas

- Tkinter

- Scikit-learn

- Matplotlib

\section{Architecture}

The Fig. 9 shows the architecture diagram used in this model.

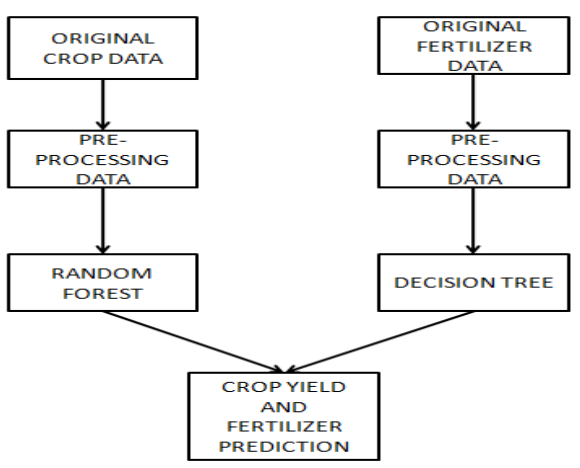

Fig. 9 Architecture

\section{Metadata}

In this stage we are going to encode all the categorical data (state name, district name, season and crop) into a unique number that is one unique number is given to one state, district, season and crop as shown in fig 10. The same number is not given to the other elements. By converting original data into metadata we can easily process the dataset. This converted data consists of more than 35 states, 600 districts, 5 seasons and around 100 crops all over India.

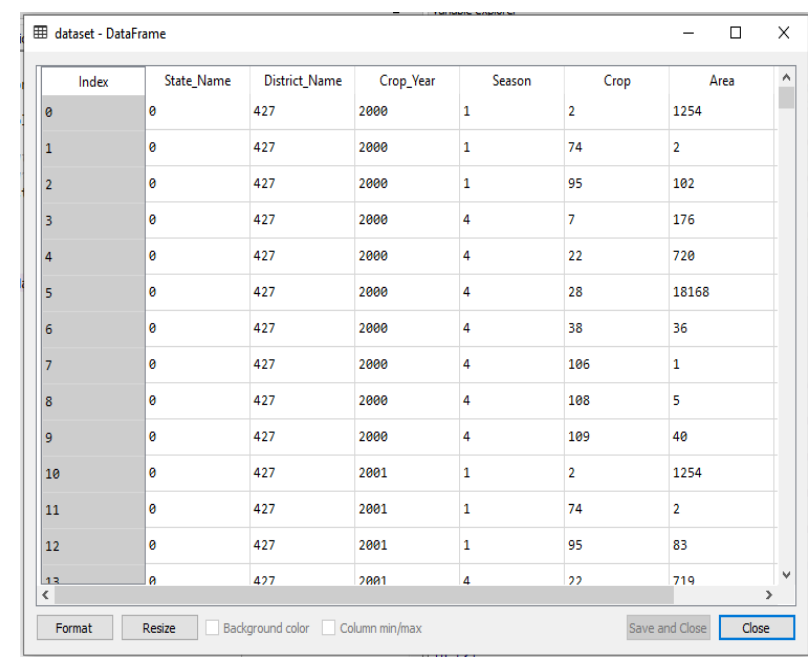

Fig. 10 Metadata 


\section{International Journal of Engineering Applied Sciences and Technology, 2020 \\ Vol. 5, Issue 1, ISSN No. 2455-2143, Pages 187-193 \\ Published Online May 2020 in IJEAST (http://www.ijeast.com)}

\section{E. Data Pre-processing}

In this stage the original crop data set is preprocessed (like taking care of missing data) and the converted data (metadata) is added to it by removing all the factors that are converted to the integer (state, district, season and crop) as shown in fig 10 . So, by doing this we can easily train the data.

For splitting the dataset into training set and test set we need to use package sklearn model selection and import train_test_split, this helps to successfully split the training data and test data according to the given split value. The split size of the test data should be $20 \%$ and training data should be $80 \%$.

\section{F. Random Forest Regression}

Random Forest regression is a flexible and easy algorithm which provides a potent prediction. Random Forest regression is a machine learning technique used for prediction.

Working of random forest regression:-

- First takes random sampling from the training dataset, depending upon the value given in estimators (n) and random state.

- Constructs $\mathrm{n}$ decision trees from sampled data.

- Each decision tree returns some predicted value, on averaging all prediction we get random forest Prediction.

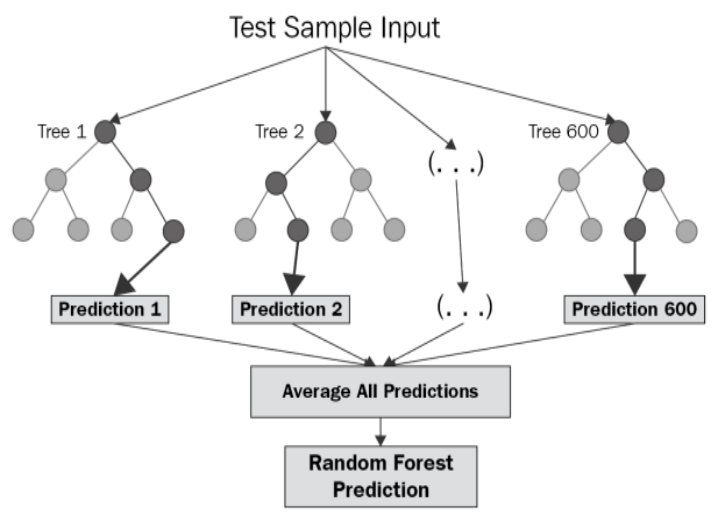

Fig.11 Random forest working model

\section{G. Fertilizer prediction using Decision Tree Algorithm}

The Fertilizer dataset which is in the CSV format is cleaned and made ready to train the data frame. Here split size of training dataset is $80 \%$ and test dataset is $20 \%$.
Decision Tree algorithm used to train the dataset. Decision tree algorithm consists of supervised learning algorithm for predicting output target features data into incrementally smaller nodes. Top node is root node, internal nodes are decision nodes and terminal nodes are leaf nodes. Tree pruning and time series cross-validation are used for lowering variance error source generated by a greater model complexity. This algorithm consists of greedy top-down approach for finding optimal recursive binary node splits by locally minimizing variance at terminal nodes measured mean square error function at each stage.

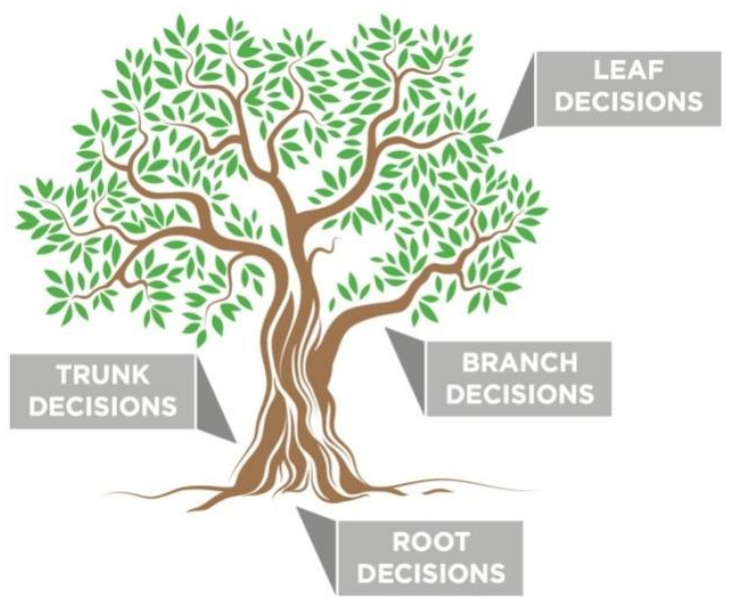

Fig. 12 Decision tree structure

\section{COMPARISON With OTHER AlgORITHM}

Here we are comparing Random Forest Regression with other algorithms like Multiple Linear Regression and Polynomial Regression.

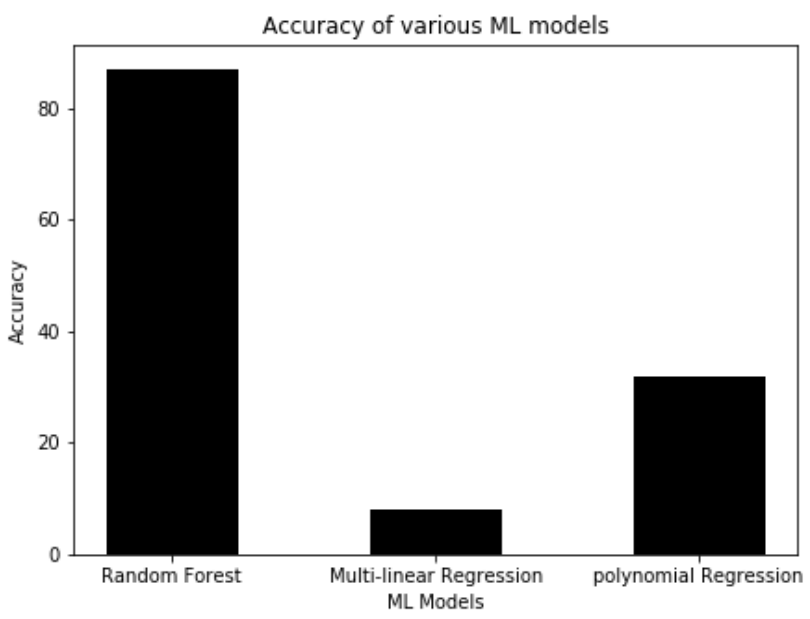

Fig.13 Accuracy of various ML models 


\section{International Journal of Engineering Applied Sciences and Technology, 2020 \\ Vol. 5, Issue 1, ISSN No. 2455-2143, Pages 187-193 \\ Published Online May 2020 in IJEAST (http://www.ijeast.com)}

As shown in fig 13 the accuracy of Random Forest Regression is 87, Multiple Linear Regression is 8 and Polynomial Regression is 32. Accuracy is calculated by cross validation scores (mean squared error). From the above accuracy figures it is proved that random forest regression has higher accuracy and performance compare to other algorithms.

\section{PERformance AnAlysis \& Result}

Here result is represented by using tkinter user interface. Crop yield prediction is done by Random Forest regression and fertilizer prediction is done Decision Tree algorithm. Random Forest model was experimented with different types of attributes like state, district, year, season, crop and area in various regions across India to predict the result. Fertilizer dataset is train with six attributes to predict the fertilizer used on the crop land. For crop yield prediction the user should enter seven fields (state name, district name, year, season name, crop name and area) to get the output is shown in Fig. 14. The result of the crop yield prediction is shown in Fig. 15. The input of the fertilizer data takes six factors; temperature, humidity, moisture, nitrogen value, potassium value and phosphorous value as shown in fig 16 and the result of the fertilizer data is shown in fig 17.

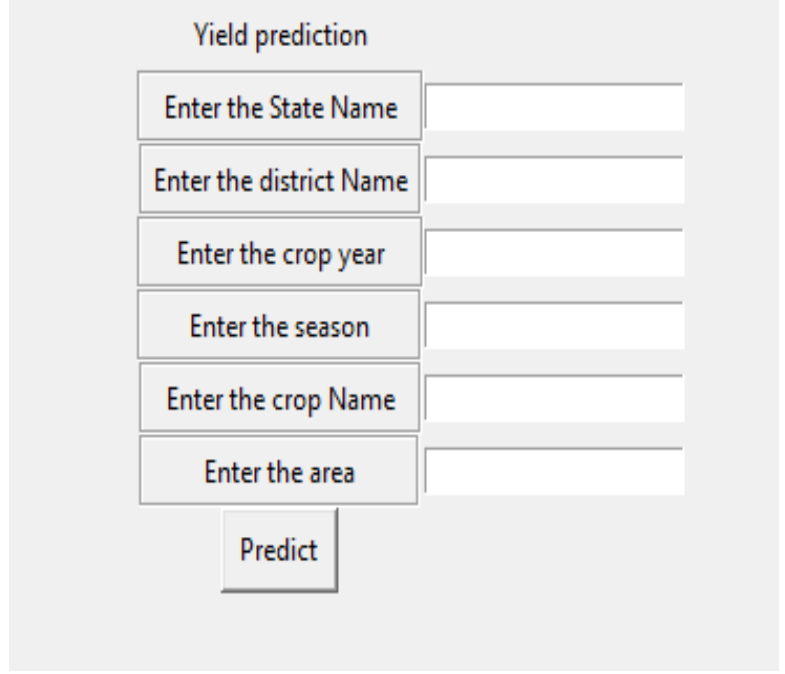

Fig. 14 Crop data input

\begin{tabular}{|c|c|}
\hline \multicolumn{2}{|l|}{ Yield prediction } \\
\hline Enter the State Name & Tamil Nadu \\
\hline Enter the district Name & VELLORE \\
\hline Enter the crop year & 2019 \\
\hline Enter the season & Kharif \\
\hline Enter the crop Name & Rice \\
\hline Enter the area & 3976 古 \\
\hline Predict & \\
\hline prediction of crop yield & [163364.7] \\
\hline
\end{tabular}

Fig. 15 Result for the given crop input

\begin{tabular}{|c|}
\hline Enter temperature \\
\hline Enter humidity \\
\hline Enter moisture \\
\hline Enter nitrogen \\
\hline Enter potassium \\
\hline Enter phosphorous \\
\hline Predict \\
\hline
\end{tabular}

Fig. 16 Fertilizer input 


\section{International Journal of Engineering Applied Sciences and Technology, 2020 Vol. 5, Issue 1, ISSN No. 2455-2143, Pages 187-193 \\ Published Online May 2020 in IJEAST (http://www.ijeast.com)}

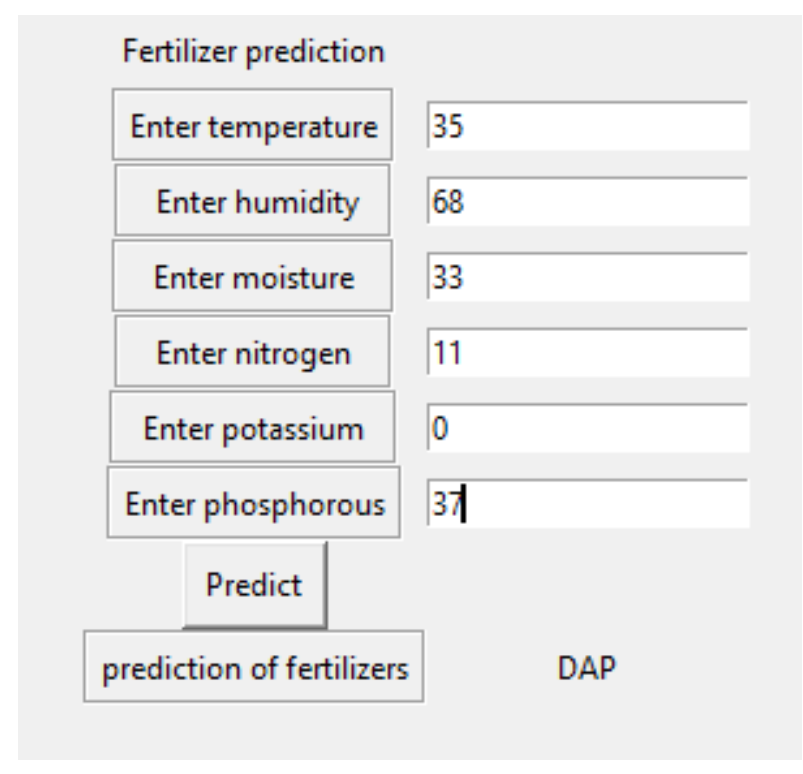

Fig. 17 Result for the fertilizer input

\section{CONCLUSION}

Prediction of crop yield and fertilizer prediction is successfully predicted by using efficient machine learning algorithm (Random Forest Regression and Decision Tree Algorithm). The experimental output tells that Random Forest Regression got highest accuracy percentage and performance compared to other algorithms used. The result is developed using python Tkinter which is a GUI tool kit. In future we can develop using the app application which makes the user to use this application more effectively.

\section{ACKNOWLEDGEMENT}

I wish to acknowledge Dr. R Obulakonda Reddy and Mohan Kalyan for their supervision. I also wish to thank Ram Chandra Prasad and Pradeep Gopal for their contribution in making this research published.

\section{REFFERENCE}

[1] Niketa Gandhi et al. (2016)," Rice Crop Yield Forecasting of Tropical Wet and Dry Climatic Zone of India Using Data Mining Techniques",IEEE International Conference on Advances in Computer Applications (ICACA) .

[2] K.E. Eswari. L.Vinitha. (2018) "Crop Yield Prediction in Tamil Nadu Using Baysian Network ", International Journal of IntellectualAdvancementsand Research in Engineering Computations, Vol-6,Issue-2,ISSN: 23482079.
[3] Shruti Mishra, Priyanka Paygude, Snehal Chaudhary, SonaliIdate. (2018) "Use of Data Mining in Crop Yield Prediction" IEEE Xplore Compliant - Part Number:CFP18J06-ART, ISBN:978-1-5386-0807-4; DVD PartNumber: CFP18J06DVD ,ISBN:978-1-53860806-7.

[4] Anna Chlingaryana, Salah Sukkarieha, Brett Whelanb(2018) - Machine learning approaches for crop yield prediction and nitrogen status estimation in precision agriculture: A review , Computers and Electronics in Agriculture 151 61-69,Elisver.

[5] Dakshayini Patil et al (2017),"Rice Crop Yield Prediction using Data Mining Techniques:An Overview", International Journal of Advanced Research in Computer Science and Software Engineering, Volume 7, Issue 5.

[6] A.T.M Shakil Ahamed, NavidTanzeem Mahmood, Nazmul Hossain, Mohammad Tanzir Kabir, Kallal Das, Faridur Rahman, Rashedur M Rahman (2015)“Applying Data Mining Techniques to Predict Annual Yield of Major Crops and Recommend Planting Different Crops in Different Districts in Bangladesh" 978-1-4799-86767/15/\$31.00 copyright 2015 IEEE SNPD .

[7] SnehalS.Dahikar, Dr.SandeepV.Rode(2014) ,Agricultural Crop Yield Prediction Using Artificial Neural Network Approach ", International journal of innovative and research in electrical, instrumentation and control engineering, volume 2,Issue2.

[8] Ramesh A. Medar (2014) "A survey on data mining techniques for crop yield prediction", International Journal of advance in computer science and management studies, ISSN:2231-7782, volume 2, Issue 9.

[9] S.kanagaSubba Raju et al.(2017), Demand based crop recommender system for farmers, International Conference on Technological Innovations in ICT For Agriculture and Rural Development.

[10] S. Bhanumathi, M. Vineeth, N. Rohit. "Crop Yield Prediction and Efficient use of Fertilizers", (2019) International Conference on Communication and Signal Processing (ICCSP).

[11] E Manjula and S. Djodkitachoumy(2017)International journal of computation Intelligence and informatics, Vol 6:No 4.

[12] ShriyaSahu et al.(2017)," An Efficient Analysis of Crop Yield Prediction Using Hadoop framework based on random Forest approach, International Conference on Computing, Communication and Automation.

[13] Jig Han Jeong et al. (2016), "Random Forests for Global and Regional Crop YieldPredictions", PLOS-ONE DOI: 10.1371/journal.pone.0156571.

[14] Pooja M C et al. (2018) - Implementation of Crop Yield Forecasting Using Data Mining, International Research 
International Journal of Engineering Applied Sciences and Technology, 2020

Vol. 5, Issue 1, ISSN No. 2455-2143, Pages 187-193

Published Online May 2020 in IJEAST (http://www.ijeast.com)

Journal of Engineering and Technology (IRJET),p-ISSN: 2395-0072.

[15] Rahul Tangia. (2019, OCTOBER 4). India's Biggest Challenge: The Future of Farming. Retrieved from https://www.theindiaforum.in/article/india-s-biggestchallenge-future-farming 